\title{
Water value, resource rent recovery and economic welfare cost of environmental protection: A water-sector model for the Steelpoort sub-basin in South Africa
}

\author{
RM Hassan ${ }^{1 *}$ and S Farolfi ${ }^{2}$ \\ ${ }^{1}$ Centre for Environmental Economics and Policy Analysis in Africa (CEEPA), University of Pretoria, South Africa \\ ${ }^{2}$ Centre for Environmental Economics and Policy in Africa (CEEPA) and CIRAD TERA, University of Pretoria, South Africa
}

\begin{abstract}
This study developed an analytical framework and an empirical water sector model to evaluate current and alternative water allocation regimes in the Steelpoort sub-basin (SPSB) in terms of the key objectives of the national water act of South Africa. The analyses showed that bulk water is currently not only oversupplied to offstream uses in the SPSB at the expense of the ecological Reserve (instream benefits) but also underpriced. The water research levy, the only mechanism used for rent capture, recovers a negligible proportion of the water resource rent (RR) (less than 2\% at best) implying that almost all $R R$ dissipates to various offstream users in the form of indirect subsidies of about $\mathrm{R} 0.42 / \mathrm{m}^{3}$ with the more realistic lowprice elasticity assumption. Commercial irrigation enjoys the highest subsidy being the major consumer followed by mining and hence the most to be affected by policy change in this regard. Results also indicate that the total maximum economic value offstream users are willing to pay for increasing water yields to supply the full requirement levels currently enjoyed at the SPSB is estimated at about R2.8/ $\mathrm{m}^{3}$. Although this value does not properly measure the net social gain or loss of environmental protection, it serves as a benchmark value against which per unit costs of potential alternative water supply options can be compared. A few caveats remain as key limitations of the study call for further research work. First, this study did not generate information on instream benefits to compare with offstream values lost as a result of protecting the ecological Reserve. Second, the study can benefit from improved specification of the water sector model parameters, particularly the supply side as better information will allow estimation of an upward sloping supply (marginal cost) curve.
\end{abstract}

Keywords: water value, resource rent and subsidies, water sector model, price elasticity of demand

\section{Introduction}

Protection of basic human and ecological needs, economic efficiency and social equity are the most important pillars guiding water resource allocation and use under the new National Water Act (NWA) of South Africa (SA). The NWA promotes integrated and decentralised water resource management under a new institutional environment. New management entities (catchment management agencies-CMAs and water user associations - WUAs) are currently established at regional and local levels, emphasising a largely decentralised and participatory approach to water resource management (Hamann and O’Riordan, 2000; Perret, 2002). The decisionmaking process for water management in SA therefore involves dealing with a complex system of interactions between multiple biophysical and socio-economic needs co-existing in a watershed. This process must also comply with and serve the economic efficiency, social equity, and environmental sustainability objectives of the NWA. Management and control of water demand has been identified as a major task of the newly established CMAs. The approach adopted for water allocation to economic uses relies on a licensing process through which water use authorisations are granted to various applicants. This process involves addressing a number of key questions such as establishing priorities and appropriate

* To whom all correspondence should be addressed.

嘼+2712 420-3317; fax:+2712 420-4958;

e-mail: rhassan@postino.up.ac.za

Received 18 October 2004; accepted in revised form 18 November 2004. regimes for allocation of water between competing uses (Farolfi and Perret, 2002).

However, water allocation decisions are currently made on the basis of very limited information on the behavioural structure underlying the decentralised decisions of the many water users involved. Proper modelling and adequate understanding of the motivations and rules that govern the choices of individual decision makers will provide better guidance for more informed water allocation regimes and policies centrally made by water management agencies. Decision support tools that can integrate in one framework the ecological and socio-economic dimensions of water resource use are accordingly needed to facilitate the design and implementation of water management strategies. This study develops a partial equilibrium water sector model to assist water managers and policy makers in SA design and evaluate alternative water allocation strategies. The Steelpoort area, a sub-basin of the Olifants River catchment in the north-east of SA, where a water stress situation exists as total annual water requirements exceed available yield and the deficit is currently supplied at the expense of the ecological Reserve was chosen as the case study area. The sub-basin is accordingly under pressure for preparation of a water management plan that would alleviate the current stress on the Reserve component, improve the economic efficiency of water use and meet the objective of social equity in water allocation.

The developed model extends earlier work on action research and watershed analyses for resource and economic sustainabilityAWARE (Farolfi and Hassan, 2003) to explore the impact of different strategies of water allocation on the key objectives of the 


\begin{tabular}{|c|c|c|c|}
\hline \multicolumn{4}{|c|}{$\begin{array}{l}\text { TABLE1 } \\
\text { Steelpoort sub-basin water resources: Supply, use and balance (2000) }\end{array}$} \\
\hline \multicolumn{2}{|l|}{ Supply sources } & \multicolumn{2}{|c|}{ Demand requirements } \\
\hline & $10^{6} \mathrm{~m}^{3}$ & & $10^{6} \mathrm{~m}^{3}$ \\
\hline MAR & 396 & Irrigation - large scale & 65 \\
\hline S1. Surface water yield (10.6\% of MAR) & 42 & Irrigation - small scale & 3 \\
\hline & & Mining & 12 \\
\hline S2. Groundwater & 14 & Industry & 5 \\
\hline & & Livestock & 1 \\
\hline S3. Usable return flows $(A+B+C)$ & 5 & Forestry & 1 \\
\hline A. Irrigation & 3 & Domestic - urban & 3 \\
\hline B. Urban water & 1 & Domestic - rural & 5 \\
\hline C. Mining and bulk & 1 & & \\
\hline WS. Total available water $(\mathrm{S} 1+\mathrm{S} 2+\mathrm{S} 3)$ & 61 & $\begin{array}{l}\text { WD. Total demand } \\
\text { (requirements) }\end{array}$ & 95 \\
\hline Balance/deficit (TWS-TWD) & -34 & & \\
\hline Reserve (R1+R2+R3) & 96.61 & & \\
\hline R1. Ecological Reserve (in-stream flow requirements - IFR) & 94 & & \\
\hline R2. Basic human needs & 2.61 & & \\
\hline R3. Other needs (strategic, international, contingency) & $\mathrm{ND} *$ & & \\
\hline $\begin{array}{l}\text { * ND means currently undetermined. } \\
\text { Source: DWAF (2002) }\end{array}$ & & & \\
\hline
\end{tabular}

NWA at the watershed level. Earlier versions of this simulation tool (AWARE) adopted a relatively simpler structure using restrictive assumptions about water demand and output supply behaviour of competing water users. The simplicity of the structure of AWARE was attractive to policy uses and negotiation processes and it is also less data intensive. The used assumptions, however, limited the ability of the model to provide more realistic representation and simulation of the actual decision-making environment. As a result, the earlier model could only evaluate regulatory command-andcontrol (CAC) options such as quantitative restrictions like quota allocations. Some of these assumptions were relaxed in formulating the present water sector model to show how solutions might differ under alternative, more realistic complications of the structures of water demand. This also allowed the evaluation of market-based instruments such as efficiency pricing in addition to CAC measures. The paper also uses the partial equilibrium model to derive and compare values of water and subsidies enjoyed by various uses, assess the rate of recovery of water resource rents and measure the economic welfare cost of protecting the ecological Reserve under different water pricing and allocation regimes.

The status of water resources availability and use in the Steelpoort sub-basin (SPSB) is reviewed and subsequently the analytical framework and structure of the water sector model are presented and discussed. The empirical model is then calibrated to available data to generate parameter estimates, conduct policy simulations and draw conclusions and implications of the study.

\section{Water availability and use in the Steelpoort sub- basin}

The Steelpoort region extends over $7139 \mathrm{~km}^{2}$, comprising about $13 \%$ of the Olifants water management area on the north-eastern boundary of South Africa, with an altitude ranging between 900 to $1200 \mathrm{~m}$ a.m.s.l. and rainfall between 600 and $1000 \mathrm{~mm} / \mathrm{a}$ (Stimie et al., 2001). Two main watercourses, the Steelpoort River and the Speckboom River, feed the sub-basin with their waters. Mean annual runoff (MAR) at the sub-basin is estimated at $396 \times 10^{6} \mathrm{~m}^{3}$ yielding $42 \times 10^{6} \mathrm{~m}^{3}$ after accounting for instream flow requirements (IFR or the ecological Reserve) of $94 \times 10^{6} \mathrm{~m}^{3}$ (Table 1). Surface water yield together with groundwater and return flow supplies give an annual yield of $61 \times 10^{6} \mathrm{~m}^{3}$. This annual level of water supply includes a surface storage capacity at dams totalling $26 \times 10^{6} \mathrm{~m}^{3}$ from 45 different-size dams in the basin (DWAF, 2002).

On the demand side, irrigation agriculture is the major user in the SPSB, contributing to more than $70 \%$ of the total water demand in the year 2002, mainly for large commercial schemes, followed by mining (12.6\%), industry and rural communities (5\% each). Note that water Reserve requirements to meet basic human needs are included in the total requirements for domestic rural and urban use. Table 1 indicates the water stress situation in the SPSB where total annual water demand exceeds available yield by $34 \times 10^{6} \mathrm{~m}^{3}$, a deficit that is currently supplied at the expense of the ecological Reserve. This in turn means that the ecological Reserve is not maintained at the required optimal level for proper sustenance of rivers and protection of aquatic ecosystems in the sub-basin. The various components of the water Reserve, which are given priority over all other uses in water allocation according to the National Water Resources Strategy - NWRS (DWAF, 2002), include provisions for ecological and basic human needs, international obligations and other strategic future demand needs. The Reserve is accordingly calculated based on a national water classification system that groups different water resource areas into different water management classes reflecting differences in required levels of social and environmental protection (DWAF, 2002). 


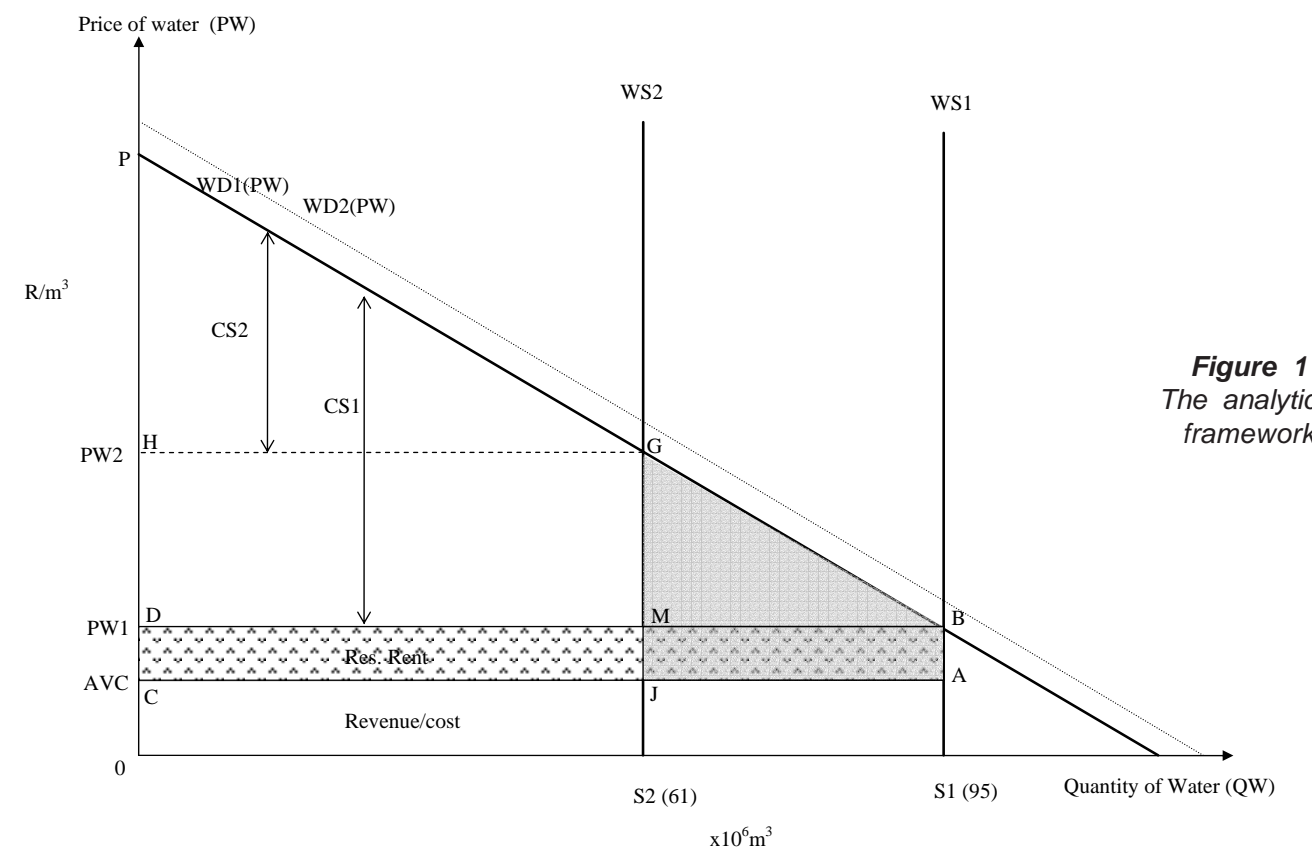

\section{Structure of the SPSB water sector model}

A partial equilibrium water sector model was constructed to represent water supply and demand systems reflecting current water supply and use patterns shown in Table 1, which comprise eight water demand sectors. Compared to earlier efforts employing simpler structures (Farolfi and Hassan, 2003), the main feature of the present water sector model is its improved specification of the demand system. Also, market-clearing conditions were imposed to solve the model for equilibrium price and quantity levels. The model was then used to evaluate alternative water allocation regimes and determine efficiency prices. The components of the SPSB water sector model are described below.

\section{The water supply component}

In the present model total water supply (WS) was set exogenously to remain at current yield levels of $61 \times 10^{6} \mathrm{~m}^{3}$ (after providing for the IFR of $94 \times 10^{6} \mathrm{~m}^{3}$ ):

$$
W S=Q S
$$

where:

QS a constant corresponding to the water yield in the sub-basin.

\section{The water demand system}

Water demand functions were specified for the eight economic use sectors, indicated in Table 1, which compete for water in the subbasin. All users in the same sector were considered homogeneous in terms of their demand for water behaviour and hence have the same water demand structure:

$$
W D_{i}=D_{i}\left(P W_{i}, \beta_{i}\right)
$$

where:

$W D_{i}$ defines the representative water demand function for members of sector $\mathrm{i}(\mathrm{i}=1,2, . ., \mathrm{n})$ to depend on the price of water (or water charge) they face $\left(P W_{i}\right)$ and their respective water demand behaviour parameters in vector $\beta_{\mathrm{i}}$.
Total demand for water (WD) in the sub-basin was then derived by aggregating water demand over the $\mathrm{n}$ sectors:

$$
W D=\sum_{i=1}^{n} W D_{i}
$$

Results of model simulations aggregating sectoral demands at different water prices $\left(P W_{i}\right)$ were used to construct an aggregate water demand function for all uses in the sub-basin. The aggregate water demand curve $W D(P W)$ was then used to determine equilibrium water price and quantity at the sub-basin and perform the intended efficiency pricing analyses using the market clearing condition specified below.

\section{Equilibrium in the water sector at the sub-basin}

Market clearing conditions were imposed to solve the model for equilibrium water price and quantity and to enable comparative analyses of the existing and alternative water allocation regimes against economic efficiency (equilibrium price) solutions.

$$
W S=Q S=W D(P W, \beta)
$$

Under this condition, an equilibrium price of water $(P W)$ can be determined endogenously forcing demand to adjust accordingly to clear the market. This allows comparing economic efficiency regimes of water allocation with alternative options. Various scenarios of water supply and allocation strategies can also be evaluated under this analytical framework in terms of net economic welfare gains and losses. The following section presents the framework adopted for conducting the intended analyses.

\section{The analytical approach and scenarios of the water sector model}

As presented above, the SPSB water sector model was constructed to satisfy partial equilibrium conditions in the water sector at the sub-basin. Figure 1 depicts the analytical foundations of the water sector model and its potential to address specific research questions of relevance to water allocation strategies following economic 
efficiency rules. As shown in Table 1 the current water supply and demand situation is represented by the WS1 and WD1 curves showing the total supply and demand for water at the sub-basin, respectively.

Point $A$ on Fig. 1 represents the current water allocation system in the SPSB where total water requirements of all economic uses (95 $\mathrm{x} 10^{6} \mathrm{~m}^{3}$ ) were supplied at an average supply cost (AVC) charged to users. At this point, even if one assumes that $A V C$ fully recovers all supply costs (including normal profits, i.e. normal returns to capital investment), which is rarely the case, consumers are paying rates lower than the market price of water (PW1) and hence enjoy an indirect subsidy (area $D B A C$ ) on top of the consumer surplus-CS1 $(P B D)$. This subsidy value represents the water resource rent $(R R)$ dissipating to water users. To provide current total requirements of all users at economic efficiency prices the water charge needs to be set at the market clearing equilibrium price $P W 1$. In which case the water service provider would recover all its costs (area $C$-A-S1-0) plus the RR (area $D B A C$ ), which may be recovered by an appropriate public agency (government) on behalf of the public through some tax or royalty regime and water users remain with their CS (area $P B D$ ). This indicates that economic uses of water in the SPSB enjoy a subsidy equivalent to the total $R R$ under the current water allocation system. Because different economic use sectors are charged different tariff rates, our framework allows calculation of sector specific subsidy levels employing the respective sector water demand functions specified in Eq. (2).

Moreover, the current water allocation system not only deviates from economic efficiency principles, but also introduces another social cost as total water requirements currently exceed available water supply (yield) with a deficit supplied at the expense of the ecological Reserve. The value of this social loss is not yet known and this research project did not attempt to establish values of ecological services lost as a result of the reduction in the instream flow requirements (IFR). Nevertheless, the analytical framework presented above allows for calculation of the opportunity cost of maintaining the ecological Reserve to fully meet IFR. In this case scenario of protecting the ecological Reserve, only water yield will be available for economic uses, which will shift the water supply curve leftward from WS1 to WS2 to supply $61 \times 10^{6} \mathrm{~m}^{3}$. If the available yield is to be allocated on economic efficiency basis, users will have to be charged the equilibrium price of water $P W 2$ at point $G$ of Fig. 1. At this equilibrium point CS will shrink to CS2, water $R R$ recovered will equal the area $H G J C$ and the resulting net social welfare loss measured by the area $G B A J$ represents the opportunity cost of maintaining the ecological Reserve to fully meet IFR.

The net social welfare loss or opportunity cost of protecting the Reserve should ideally be compared to welfare gains from the economic benefits of the preserved ecological services of the Reserve. As said earlier, the present study unfortunately could not establish a value for these ecological services. Nevertheless, the total loss of economic welfare resulting from water allocation regimes that give priority to protecting the Reserve and its instream ecosystem services provides a bench-mark or baseline estimate of the potential economic benefits to be realised from increasing available water at the sub-basin, against which the cost of investment outlays to increase current water yield levels can be compared and justified. The same principle may be applied to measuring water benefits from alien-vegetation clearing programmes as those effectively shift the water supply curve to the right. This provides a more appropriate basis for calculating net social gains from such a shift to capture water-related opportunity cost of alien plant invasion compared to what is proposed in Hoskin and Du Preez (2004).

In addition to providing information on the value of investing in additional water supplies (offstream economic benefits lost as less water is made available in order to protect instream ecosystem services), this also indicates potential economic welfare benefits from investing in technological means to improve water use efficiency as an alternative water management strategy. While increasing water yield will shift the supply curve to the right in the direction of WS1, technological improvements will cause the demand curve to shift outwards (WD2) leading to higher economic value of water (larger economic surplus and $R R$ ).

This study will employ the above analytical framework characterising the current decision environment of water allocation and use in the SPSB to develop an empirical water sector model and use it to analyse various water policy questions under the following scenarios and water allocation regimes:

\section{Scenario I}

In this scenario economic efficiency rules are followed as the strategy to allocate water to meet total current requirements of 95 $\mathrm{x} 10^{6} \mathrm{~m}^{3}$ (WS1). This scenario allows performing the following analyses:

- Determine the market clearing equilibrium price $P W 1$

- Use PW1 to calculate subsidy levels enjoyed by economic uses under the current water allocation strategy and charges, i.e. how far are current tariff rates from the equilibrium price?

- Derive a measure of the water $R R$, its distribution and rate of recovery

- Calculate the total value of water to economic uses in the SPSB (the sum of $C S$ and $R R$ ).

It is important to note that this policy does not lead to loss in economic welfare apart from the social welfare loss due to reduced ecosystem health caused by lower Reserve, which this study could not evaluate. Accordingly, it was not possible under this scenario to evaluate the trade-off between offstream and instream benefits of water. The more interesting consequence of this policy, however, is its distributional effects as it allows reallocation of economic benefits through the capture and spending of the $R R$ by the appropriate public agency or government.

\section{Scenario II}

The strategy of this scenario gives priority to protecting the ecological Reserve and hence allocates only water yield (WS2) among competing economic uses, again guided by the principles of economic efficiency. While preserving instream ecological values, this strategy leads to lower economic welfare as explained earlier. This welfare loss represents the opportunity cost of protecting freshwater ecosystems in the SPSB. Under this strategy the following analyses will be performed:

- Determination of the equilibrium price PW2 that establishes economic efficiency in water allocation

- Evaluation of how far current water tariffs are from economic efficiency (subsidy levels) under ecologically sustainable water allocation regimes

- Calculation of the welfare loss caused by environmental protection as the opportunity cost of maintaining the ecological Reserve

- Evaluation of the change in water $R R$, its recovery and distribution under this strategy

Results from the first two scenario analyses will be used to evaluate the costs and benefits and hence social desirability and attractiveness of these two alternative water management regimes in the subbasin. 


\section{The empirical water sector model of the SPSB}

This section specifies sectoral water demand functions, then calibrates the specified empirical model to available data to determine the water demand system parameters for the various use sectors. An aggregate water demand function for the SPSB is then derived by aggregating sectoral water demands.

The SPSB model includes eight water use sectors, as indicated in Table 1 . The demand for water by these sectors is modelled as a function of the water price assuming the following linear demand function:

$$
W D_{i}=a_{i}-b_{i} P W_{i}
$$

where:

$W D_{i}$ determines the quantity of water demanded by sector $i$ as a linear function of the water price faced by the sector $\left(P W_{i}\right)$. $a_{i}$ and $b_{i}$, respectively, measure the intercept and slope of the demand curves.

\section{Calibration of the demand system to available data}

The following data sources were used to conduct the empirical analyses and simulations:

- Levels of water use and charges (Table 1 and Appendix). Information on current levels of water use and charges by sector was compiled from surveys of primary and secondary sources, i.e. water users and water management agencies at the sub-basin

- The surveys also generated information on domestic water use by urban and rural households, which allowed estimation of water demand parameters for domestic users

- Estimates of water demand parameters generated by a number of recent water demand studies in the country and elsewhere (see ranges reported in Appendix) were used in the sense of "benefit transfer" to complement this study's efforts to specify the demand behaviour of water users at the SPSB (Dockel, 1973; Hassan et al., 1996; Amir and Fisher, 1999; Veck and Bill, 2000; King, 2004; Tewari, 2003; Mirrilees et al., 2003; Veck and Williams, 2004; Van Vuuren et al., 2004).

Data on current costs of water to various users were compiled for the SPSB. There is a wide range among use sectors in terms of the cost of water. Some users are provided with water from a public network or from a dam (government schemes). On the other hand, other users are self-providers. Government water tariffs/charges levied by DWAF on bulk water supplies to different use sectors were used as water prices $(P W)$. Details of the structure of water charges in the SPSB for sectors abstracting water for commercial use are found in the Appendix and consist of the following components (DWAF, 2003):

- The consumptive (use) charge, which applies only to users receiving water from government water schemes. This charge recovers costs associated with maintenance and operation of the water supply schemes

- The water resource management charge (WRMC), which applies to all users except Schedule 1 users. Schedule 1 users as defined in the NWA are those abstracting water directly from a natural source (including storage and use of rainwater) for noncommercial purposes such as household consumption, gardening and subsistence stock watering, (DWAF, 2003). This charge is introduced to recover actual costs of water resource management activities (e.g. planning and control of water allocations and use, monitoring and control of pollution and invasive alien plants, water conservation and demand management, etc.). Note that this charge also applies to streamflow reduction activities such as cultivated forests (plantations) and commercial dryland agriculture

- The water research levy, which is collected from users, supplied with water from government schemes and water service providers (i.e. municipalities and WUAs including irrigation boards)

While the first two represent recovery of actual water supply costs, the water research levy is treated as a royalty recovering part of the resource rent.

The SPSB water demand system model was calibrated to data on estimates of price elasticity of water demand obtained from a number of sources at observed current levels of water use and price charges to generate the demand system parameters (slope $b$ and intercept $a$ ). Details of the calibration process are presented in the Appendix.

Using the specified sectoral water demands, a total water demand function for the SPSB was then derived by aggregating over all sectors:

$$
W D=a-b P W=\Sigma_{i} W D_{i}=\Sigma_{i}\left(a_{i}-b_{i} P W_{i}\right)
$$

Simulation of quantities of water demanded by the various sectors $W D_{i}$ at different price levels $P W_{g}$, aggregated over all sectors gives total demand by all sectors $W D_{q}$. Simulated values of $W D_{q}$ and $P W_{g}$ were then used to fit an aggregate water demand curve and derive its parameters $a$ and $b$. Since specification of the aggregate water demand curve is sensitive to the chosen sectoral elasticity parameters, this method resulted in the total water demand functions given in the Appendix for the SPSB.

The area under this demand curve is equal to the sum of the areas of all sector demand curves:

$$
\int_{0}^{Q W} P W(Q W) d Q W=\sum_{i=1}^{n} \int_{0}^{Q W_{i}} P W_{i}\left(Q W_{i}\right) d Q W_{i}
$$

where:

$Q W$ refers to quantity of water demanded.

\section{Results of the empirical model under alternative water allocation regimes}

The two above discussed scenarios (efficiency pricing at current levels of water use of $95 \times 10^{6} \mathrm{~m}^{3}$ and at the maximum yield of 61 $\mathrm{x} 10^{6} \mathrm{~m}^{3}$ ) were evaluated using the estimated water sector model. The model was used to determine equilibrium prices at the two levels of total water allocation and in turn calculate the various values depicted in Fig. 1 under each scenario (e.g. $R R, C S$ and water subsidies).

For simplicity of notation we will use $Q$ in place of $Q W, P$ for $P W$ and $C$ in place of $A V C$. According to the analytical framework depicted in Fig. 1, we derive consumer surplus $(C S)$ measures as follows:

$$
C S(Q)=\int_{0}^{Q}(P(Q)-C) d Q=\left.\right|_{0} ^{Q} \frac{1}{2 b} Q^{2}
$$

For Scenario I, where $Q=95$ the integral in Eq. (8) will be evaluated between 0 and 95 to calculate the $C S$ (similarly between 0 and 61 for Scenario II, where $Q=61$ ). On the other hand, the resource rent $(R R)$ is derived as the difference between the equilibrium price at $Q$ level of 95 (61 for Scenario II) and costs paid by each user per $\mathrm{m}^{3}$ of water used, which when multiplied by the quantity of water used 


\section{TABLE2}

Water sector model solution values for the two water allocation scenarios in the SPSB (2003 values)

\begin{tabular}{|l|cc|cc|}
\hline & \multicolumn{2}{|c|}{ High elasticity } & \multicolumn{2}{c|}{ Low elasticity } \\
\cline { 2 - 5 } & Scenario I & Scenario II & Scenario I & Scenario II \\
\hline Equilibrium price $\left(\mathrm{R} / \mathrm{m}^{3}\right)$ & 0.843 & 4.266 & 0.512 & 5.322 \\
Subsidy (R m.) & 70.85 & 253.56 & 39.48 & 317.25 \\
$\mathrm{R} / \mathrm{m}^{3}$ & 0.74 & 4.16 & 0.42 & 5.20 \\
& & & & \\
Resource rent-RR (R m.) & 71.49 & 254.07 & 40.12 & 317.82 \\
$\mathrm{R} / \mathrm{m}^{3}$ & 0.75 & 4.16 & 0.42 & 5.21 \\
& & & & \\
\% of RR recovered & $0.90 \%$ & $0.20 \%$ & $1.61 \%$ & $0.18 \%$ \\
Consumer surplus (R m.) & 454.42 & 187.36 & 638.38 & 263.20 \\
$\mathrm{R} / \mathrm{m}^{3}$ & 4.78 & 3.07 & 6.72 & 4.31 \\
Welfare cost (R m.) & - & 83.82 & - & 96.13 \\
$\mathrm{R} / \mathrm{m}^{3}$ & - & 2.46 & - & 2.83 \\
Price elasticity of demand & -0.09 & -0.69 & -0.04 & -0.62 \\
\hline
\end{tabular}

by each sector gives the total subsidy enjoyed by that sector and when summed over all sectors gives an estimate of the total subsidy at the sub-basin. Results of the above calculations for the two scenarios are summarised in Tables 2 and 3 under the two scenarios described above. Tables 2 and 3 also report results under two elasticity assumptions: a high elasticity (HES) using the upper bound and low elasticity (LES) based on the lower bound of elasticity ranges given in the Appendix.

The simulation results reported in Table 2 indicate that at current water allocation levels $\left(95 \times 10^{6} \mathrm{~m}^{3}\right)$ the market value of bulk water in the SPSB is about R0.84 under the HES assumption, generating more than R70 $\mathrm{m}$. of resource rents (RRs), almost all dissipating to various water users. At this market-clearing price an economic surplus (CS) of more than R450 m. is generated giving an average of $\mathrm{R} 4.78 / \mathrm{m}^{3}$ welfare water value. When water supply was limited to the available yield of $61 \times 10^{6} \mathrm{~m}^{3}$ in order to protect the ecological Reserve, a much higher market price of $\mathrm{R} 4.27 / \mathrm{m}^{3}$ was achieved, leading to a much higher subsidy of $\mathrm{R} 4.16 / \mathrm{m}^{3}$. This, however, reduced the economic surplus to $\mathrm{R} 3.07 / \mathrm{m}^{3}$, causing a deadweight loss in the economic welfare value of water of more than R58 m. This amounts to an opportunity cost of R1.71 for every $\mathrm{m}^{3}$ of water withdrawn from economic activity for environmental protection. As discussed earlier, this measure of loss in CS from offstream values is not the appropriate measure of net social loss or gain as it does not account for the welfare gains from improved ecosystem functioning (instream values of water), which the present study could not establish. Nevertheless, these results suggest that the average economic value from increasing water supply (yield) to offstream uses in the SPSB amounts to R1.7/ $\mathrm{m}^{3}$. Adding the RR realised at the full water supply scenario to this gives a total economic value of $\mathrm{R} 2.46 / \mathrm{m}^{3}$ that can be used as a benchmark against which per unit costs of alternative water supply options may be compared. Note that the social benefit from increased water supply to offstream uses (opportunity cost) increases to $\mathrm{R} 2.83 / \mathrm{m}^{3}$ under the LES assumption.

It is also important to note that while the equilibrium price and $R R$ at the LES assumption are lower than those realised with HES under Scenario I, the reverse is true when water supply was limited to available yield levels under Scenario II. This is due to the fact that under the two elasticity assumptions the two demand curves (LES and HES) cross at quantity $Q W=87 \times 10^{6} \mathrm{~m}^{3}$, below which (e.g. the $61 \times 10^{6} \mathrm{~m}^{3}$ yield level) higher price levels obtain with the LES curve (see Fig. 2).

It is clear from Table 2 that the only part of the $R R$ collected through the water research levy captures a very small portion of the total $R R$ under all scenarios and elasticity assumptions of less than

$2 \%$ at best. The rest of the $R R$ dissipates to various water users at the SPSB in different shares as shown in Table 3. Clearly, large-scale commercial irrigation agriculture reaps the lion share of the $R R$ as it is the major user of water at the sub-basin followed by mining activities. Rural households and small irrigation farmers are currently subsidized as 61 87 95 $\mathrm{x} 10^{6} \mathrm{~m}^{3}$ Quantity of water QW

Figure 2

Water demand in the Steelpoort sub-basin for different levels of price elasticity
Schedule 1 users. The per unit subsidy is highest for irrigation farmers while mining, industry and urban households are charged for bulk water at relatively lower subsidy rates. 
TABLE3

Distribution of the resource rent subsidy among water use sectors in the SPSB (per cent of total)

\begin{tabular}{|l|c|c|c|c|}
\hline \multirow{2}{*}{} & \multicolumn{2}{|c|}{ High elasticity } & \multicolumn{2}{c|}{ Low elasticity } \\
\cline { 2 - 5 } & Scenario I & Scenario II & Scenario I & Scenario II \\
\hline Rural households & 5.95 & 8.41 & 6.49 & 8.39 \\
Urban households & 2.16 & 3.69 & 1.37 & 3.46 \\
Irrigation-small & 3.57 & 4.69 & 3.89 & 4.59 \\
Irrigation-commercial & 73.77 & 59.22 & 78.02 & 55.31 \\
Livestock & 1.13 & 1.60 & 1.20 & 1.58 \\
Mines & 8.64 & 14.80 & 5.47 & 17.88 \\
Forestry & 1.18 & 1.41 & 1.28 & 1.34 \\
Industry & 3.60 & 6.17 & 2.28 & 7.45 \\
\hline Total (R m.) & 70.85 & 253.56 & 39.48 & 317.25 \\
& $100 \%$ & $100 \%$ & $100 \%$ & $100 \%$ \\
\hline
\end{tabular}

\section{Conclusions and limitations of the study}

The preceding analyses showed that bulk water is currently oversupplied to offstream uses in the SPSB at the expense of the ecological Reserve (instream benefits). The study also indicated that bulk water is currently underpriced and the only rent capture instrument used, the water research levy, recovers a negligible proportion of the $R R$. The consequence is dissipation of almost all the $R R$ to various offstream users of water in the form of indirect subsidies of about R0.75 or R0.42/ $\mathrm{m}^{3}$ with the HES and LES assumptions, respectively. Commercial irrigation enjoys the highest subsidy being the major consumer followed by mining. Results of the simulation analysis also indicate that the opportunity cost in terms of economic surplus lost to offstream uses as a result of limiting water supply to protect the ecological Reserve is $\mathrm{R} 2.83 / \mathrm{m}^{3}$. This value, while it does not properly reflect the net social gain or loss of environmental protection, serves as a benchmark value against which per unit costs of potential alternative water supply options can be compared.

These results, however, should be viewed with caution. In spite of the relative robustness of the derived results under alternative price elasticity scenarios, the following caveats remain as key limitations of the study that call for further research work:

- An important deficiency of the study is the lack of information on instream benefits to compare with benefits lost to offstream uses and enable calculation of net social gains or loss of environmental protection through conserving the ecological Reserve

- Current specification of the supply side of the water sector model can be improved with better information to allow estimation of upward-sloping supply (marginal cost) curves rather than the fixed total supply currently used. This may not significantly alter the empirical findings but will certainly be more appropriate especially for users of delivered (processed) water such as municipal supplies to industry and domestic sectors

- The water demand side of the model can also benefit from improved parameter estimates for the mining, industry and irrigation sectors.

\section{Acknowledgements}

The National Research Foundation (NRF) and the South Africa/France Science and Technology Cooperation Programme provided partial funding for this study. We also wish to acknowledge the valuable assistance of B Banda with the analyses of the domestic water use survey data. All errors remain the sole responsibility of the authors.

\section{References}

AMIR I and FISHER FM (1999) Analysing agricultural demand for water with an optimising model. Agric. Syst. 61 54-56.

DOCKEL JA (1973) The influence of the price of water on certain water demand categories. Agrekon 12 (3) 17-22.

DWAF (2002) National Water Resource Strategy (Proposed 1st edn.) Summary. August. 37 pp.

DWAF (2003) Water Use Charges for Government Water Schemes and Water Resource Management Charges 2003-2004 - Mpumalanga Region. www.dwaf.gov.za. 7 pp.

FAROLFI S and HASSAN RM (2003) AWARE, a decision support tool towards decentralised water management in South Africa. Proc. Int. Conf. Water Governance and Sustainable Development. Sousse (Tunisia). 9-10 October.

FAROLFI S and PERRET S (2002) Inter-sectoral competition for water allocation in rural South Africa: Analysing a case study through a standard environmental economics approach. Proc. XXXIX Symp. of the Italian Society of Agricultural Economics (SIDEA). Florence. 12-14 September.

HAMANN R and O'RIORDAN T (2000) Resource management in South Africa. S. Afr. Geog. J. 82 (2) 23-34.

HASSAN R M (2003) Economy-wide benefits from water-intensive industries in South Africa: Quasi-input-output analysis of the contribution of irrigation agriculture and cultivated plantation in the Crocodile River catchment. Dev. South. Afr. 20 (2) 171-195.

HASSAN RM, BERNS J and CHAPMAN S (1996) Economic policies and the environment in South Africa: The case of water resources in Mpumulanga. LAPC Policy Paper No 24. LAPC. Johannesburg.

HOSKIN SG and DU PREEZ M (2004) The valuation of water for conservation projects in South Africa. Dev. South. Afr. 21 (2) 385398.

KING N (2004) The economic value of water in South Africa. In: Blignaut J and De Wit M (eds.) Sustainable Options: Development Lessons from Applied Environmental Economics. UCT Press, Cape Town.

MIRRILEES R, MULLINS D, RINGWOOD B, MOKAILA E, MOSAKA D and BASSON T (2003) The Value of Water as an Economic Resource in the Vaal River Catchment. WRC Report No. 990/1/03. Water Research Commission, Pretoria.

NATIONAL WATER ACT (1998) Act No. 36 of 1998. Government Gazette of the Republic of South Africa. 26 August 1998, Vol. 398, No. 19182

PERRET S (2002) Water policies and smallholding irrigation schemes in South Africa: A history and new institutional challenges. Water Policy 4 283-300.

STIMIE S, RICHTERS E, THOMPSON H, PERRET S, MATETE M, ABDALLAH K, KAU J and MULIBANA E (2001) HydroInstitutional Mapping in the Steelpoort River Basin, South Africa. Working Paper No. 6. International Water Management Institute, South Africa. Pretoria. 85 pp.

TEWARI DD (2003) An Estimation of the Value of Water in the Commercial Forestry Sector in Selected Areas in South Africa: A Case Study of KwaZulu-Natal. WRC Report No. 1133/1/03.

VAN VUUREN DS, VAN ZYL HJ, VECK GA and BILL MR (2004) Payment Strategies and Price Elasticity of Demand for Water for Different Income Groups in Three Selected Urban Areas. WRC Report No. 1296/1/04. Water Research Commission, Pretoria. 
VECK GA and BILL MR (2000) Estimation of the Residential Price Elasticity of Demand for Water by Means of a Contingent Valuation Approach. WRC Report No. 790/1/00. Water Research Commission, Pretoria.
VECK GA and MULLINS M (2004) The Value of Water as an Economic Resource in the Great Letaba River Catchment. Draft report. Water Research Commission (WRC), Pretoria.

\section{Appendix}

\section{Calibration of demand system model parameters}

The following procedure was employed to estimate the SPSB water demand system parameters. Given the linear water demand system specification:

$$
Q_{i}=a_{i}-b_{i}^{*} P_{i}
$$

and the definition of price elasticity $e_{i}$ :

$$
e_{i}=\left(\partial Q_{i} / \partial P_{i}\right)\left(P_{i} / Q_{i}\right)
$$

one can compute demand function parameters $a_{i}$ and $b_{i}$ using information on $Q_{i}, P_{i}$ and $e_{i}$ as follows:

Since $e_{i}=\left(\partial Q_{i} / \partial P_{i}\right)\left(P_{i} / Q_{i}\right)$

which means, using the linear demand function:

$$
e_{i}=b_{i} *\left(P / Q_{i}\right)
$$

solving for: $\quad b_{i}=e_{i}^{*}\left(Q_{i} / P_{i}\right)$

and hence: $\quad a_{i}=Q_{i}+b_{i}^{*} P_{i}$
Using our knowledge of current water use levels $\left(Q_{i}\right)$, prices $\left(P_{i}\right)$ and elasticity estimates $\left(e_{i}\right)$ we can then calculate the values of $a_{i}$ and $b_{i}$ for the various demand sectors at the SPSB (Table A.1).

An alternative method was used to derive parameters $a$ and $b$ of total water demand. In this method, the value of $a$ (intercept at $P W=0$ ) was calculated to be

$$
a=\sum_{i=1}^{n} a_{i}=103.37 \text { (according to Eq. 6). }
$$

Parameter $b$ was then derived using a weighted average of sectoral demand elasticities such that:

$$
\mathrm{e}=\frac{\sum_{i=1}^{n} e_{i}^{*} Q W_{i}}{\sum_{i=1}^{n} Q W_{i}}
$$

Then the value of $b$ was derived using the estimated total demand

\begin{tabular}{|c|c|c|c|c|c|c|c|c|}
\hline \multirow[t]{2}{*}{ Sector } & \multirow{2}{*}{$\begin{array}{c}\text { Range of } \\
\text { elasticity } \\
\text { estimates }\left(e_{i}\right)\end{array}$} & \multicolumn{2}{|c|}{ Intercept $\left(a_{i}\right)$} & \multicolumn{2}{|c|}{ Slope $\left(b_{i}\right)$} & \multicolumn{3}{|c|}{$\begin{array}{l}\text { Bulk water } \\
\text { charges 2002/3 }\left({\left.\mathrm{C} / \mathrm{m}^{3}\right)}^{2}\right.\end{array}$} \\
\hline & & High $e_{i}$ & Low $e_{i}$ & High $e_{i}$ & Low $e_{i}$ & $\begin{array}{l}\text { Use } \\
\text { charge }\end{array}$ & WRMC & Total $^{3}$ \\
\hline Rural households & 0.29 & 6.45 & 6.45 & 6.04 & 6.04 & 0 & 0 & 0 \\
\hline Urban households & $0.17-0.81$ & 5.43 & 4.41 & 0.71 & 0.41 & 29 & 2.08 & 33 \\
\hline Irrigation-small & $0.00001-0.06$ & 3.00 & 3.00 & 0.05 & 0.05 & 0 & 0 & 0 \\
\hline Irrigation-Large & $0.00001-0.06$ & 65.39 & 65.065 & 1.30 & 0.22 & 2.9 & 0.9 & 3.8 \\
\hline Livestock $^{2}$ & - & 1.001 & 1.001 & 0.01 & 0.01 & 2.9 & 0 & 3.8 \\
\hline Mines & $0.04-0.24$ & 14.88 & 12.48 & 1.25 & 0.21 & 29 & 2.08 & 33 \\
\hline Forestry & 0.012 & 1.012 & 1.012 & 0.04 & 0.04 & 0 & 0.8 & 1 \\
\hline Industry & $0.04-0.24$ & 6.2 & 5.2 & 0.52 & 0.09 & 30 & 2.08 & 33 \\
\hline Aggregate demand & $0.04-0.09$ & 10.337 & 98.62 & 9.93 & 7.07 & & & \\
\hline
\end{tabular}
elasticity $e$ and the equilibrium price $(P W)$ at current water use levels $(W D=95)$. The two methods gave very close values of $a, b$ and $e$.

TABLEA.1

Elasticity and water demand parameters= estimates and water charges in the SPSB

1. Note that in calibrating the empirical water sector model we have used lower bounds of 0.47 and 0.001 as averages instead of the very low tail values of 0.17 and 0.00001 for urban household and irrigation agriculture elasticity, respectively.

2. As no source was available for the livestock sector, the same range of elasticities used for the irrigation-small sector was adopted.

3. The difference between the total and the sum of user charge and WRMC represents the water research levy. 